\title{
Contagious Bovine Pleuropneumonia: Challenges and Prospects Regarding Diagnosis and Control Strategies in Africa
}

This article was published in the following Dove Press journal: Veterinary Medicine: Research and Reports

\author{
Nma Bida Alhaji' \\ Paul Idoko Ankeli ${ }^{2}$ \\ Livinus Terhemba $1 \mathrm{kpa}^{2}$ \\ Olutayo Olajide Babalobi ${ }^{3}$ \\ 'Public Health and Epidemiology \\ Department, Ministry of Livestock and \\ Fisheries, Minna, Nigeria; ${ }^{2}$ Mycoplasma \\ Laboratory, Bacterial Research Division, \\ National Veterinary Research Institute, \\ Vom, Nigeria; ${ }^{3}$ Department of Veterinary \\ Public Health and Preventive Medicine, \\ University of Ibadan, Ibadan, Nigeria
}

\begin{abstract}
Contagious bovine pleuropneumonia (CBPP) is an infectious and contagious respiratory disease of cattle, caused by Mycoplasma mycoides subsp. mycoides ( $\mathrm{Mmm})$. In this review, basic epidemiological features of CBPP, complicated by existing different strains of Mycoplasmas with similar biochemical characteristics, with preference to Sub-Saharan Africa are discussed. Many sub-Saharan African countries are challenged by variable gaps that include diagnostic tools and control strategies. Science-based issues on diagnostic procedures, vaccination, treatment, and other control strategies are discussed. Participatory epidemiology (PE), a diagnostic technique used in the identification and solving of animal health problems in rural communities, was also discussed. PE application, in conjunction with conventional diagnostic tools, will improve CBPP identification in pastoral rural communities and promote control of the disease in Africa. Furthermore, adequate CBPP control can be achieved through stronger political commitments from governments by prioritizing the disease among major diseases of high economic importance to the livestock industry for surveillance and control. Investment in CBPP control in endemic African countries will assure food security, livelihoods and the general well-being of people, and international trade.
\end{abstract}

Keywords: contagious bovine pleuropneumonia, Mycoplasma mycoides subsp. mycoides, economic impact, diagnostic tools, control strategies, sub-Saharan Africa

\section{Introduction}

Contagious bovine pleuropneumonia (CBPP) is an infectious and contagious respiratory disease, mainly of cattle, caused by Mycoplasma mycoides subsp. mycoides $(\mathrm{Mmm}){ }^{1}$ It is transmitted by direct or close contact between infected cattle and susceptible animals, and remains an important constraint to cattle production in many sub-Saharan African countries. ${ }^{2,5}$ It is a disease with very high economic importance, with the ability to compromise food security in endemic areas. $^{2}$ It was the only bacterial disease contained in the former List " $A$ " Diseases grouping of the World Organization for Animal Health (OIE) requiring urgent outbreak reporting. ${ }^{6}$

CBPP is insidious in nature with associated control difficulties, and remains a big problem for most cattle producing sub-Saharan African countries. The economic depressions of the 1980s and 1990s that affected many countries in Africa and the subsequent imposed structural adjustment programmes have led to the decline of funding in public veterinary services. These have resulted in poor to
Correspondence: Nma Bida Alhaji
Ministry of Livestock and Fisheries, AbdulKareem Lafene Secretariat Complex, Department of Public Health and Epidemiology, Minna PMB I75, Nigeria

Emailnmabida62@gmail.com

Veterinary Medicine: Research and Reports 2020: I I 7|-85 
no surveillance and control of CBPP in endemic areas. ${ }^{7}$ Other factors such as decreases in veterinary services patronage by pastoralists, impacts of movement control on pastoral livelihoods, and decline in the enforcement of animal health policies by the veterinary authorities have decreased the effectiveness of mitigation measures used against the disease. All these have consequently led to increased prominence of the disease in many parts of East, Central, and West African countries. ${ }^{8}$ With declining livestock and animal health budgets in Africa, most governments rely a lot on bilateral and multilateral international donor organizations for funds to finance animal disease control programs, which could not be sustained continuously due to inadequate or the absence of financial contributions from recipient African governments, resulting to a total lack of enforcement of control measures. ${ }^{2}$

Many efforts have been made to effectively control CBPP in Africa despite the challenges, but with varying degrees of success. Efforts made in the past include the Joint Project 28 (JP 28) of the 1970s, and the Pan African Control for Epizootics (PACE). During the JP 28 implementation, control of CBPP was carried out through a policy of compulsory mass vaccination campaign in the endemic foci of Africa, followed by quarantine, and test and slaughter with compensation of infected cattle, and disease outbreaks reporting. ${ }^{9,10}$ However, the mass vaccination encountered serious problems mainly due to refusal of the pastoralists to allow their animals to be vaccinated for fear of post-vaccination reactions. ${ }^{10}$ Unfortunately, outcomes of these efforts were not encouraging as envisaged. Furthermore, a combined control effort for rinderpest and CBPP was jointly conducted during the Pan African Rinderpest Campaigns (PARC), in which vaccine containing both rinderpest and CBPP attenuated strains was used. This ended in 1999 and rinderpest was eradicated but CBPP still persists despite continuation of a mass vaccination campaign against it, though epileptically using T1/44 CBPP vaccine. ${ }^{9,10}$ As a consequence, CBPP still persists in many cattle farms in the continent. Nevertheless, the implementation of monitoring systems of the PACE for the transhumance cattle has not been widely effective especially in Central and Western African countries due to lack of cooperation from the herders. ${ }^{9}$

For vaccination programs, the quality of vaccines used to control CBPP has declined in recent times due to militating factors that include problems of independent quality control by some manufacturers in Africa, inadequate handling of vaccines by inoculators during vaccination campaigns, such as poor cold chain maintenance, and usage of vaccines with sub-optimal quantities of $\mathrm{Mmm}$ strains. ${ }^{9,11}$ The consequence has been the occurrence of post-vaccination reactions in a few vaccinated cattle and occasional deaths. Also, some serological tests do not effectively detect vaccinated cattle, especially at sub-clinical and chronic stages, leading to poor ascertainment of sero-monitoring of effective and efficient vaccination coverage and establishment of herd immunity levels. ${ }^{9}$

The study of CBPP epidemiology in endemic situations is problematic due to its insidious nature. This has resulted in poor understanding of its basic biology, immunology, pathogenesis, and distribution. In view of these challenges, effective surveillance and control of the disease will require understanding of its epidemiology and control strategies for good inferences to be made on such factors as herd immunity levels. ${ }^{12}$ With the continuous declining resource allocation to public sector veterinary services in many African countries, information deficits are often most evident in those areas with large cattle populations, hard-to-reach (remote), and poverty high level. Expansion in livestock production system, conflicts, terrorism, and complex ecological changes such as climate change and environmental degradation, as well as socio-cultural activities of pastoralists are current challenges promoting livestock diseases such as CBPP in the livestock farming communities of Africa. ${ }^{13}$ These issues are potential factors that can modify interactions between hosts and disease agents with consequent alteration in the distribution and prevalence of CBPP. Identifying the lineages of $\mathrm{Mmm}$ strains circulating in Africa will be essential for diagnosis and control of the disease as it will provide information on the status of the available strains for effective vaccine development.

CBPP has been reported to be associated with high economic losses for herders and the livestock industry. In 1853, South Africa lost over 100,000 cattle in 2 years due to CBPP introduction into the region. ${ }^{14}$ An estimated annual loss attributable to CBPP in some African countries was around US\$ 2 billion. ${ }^{15}$ In 2006, the cost of losses due to morbidity and mortality in CBPP affected animals in 12 sub-Saharan African countries was estimated at 30 million Euros, while the total economic cost was estimated at 44.8 million Euros or 3.7 million Euros per country. ${ }^{2}$ In the northern part of Nigeria, the economic cost of CBPP in the livestock industry was estimated to be US\$ 1.5 million in $1996 .{ }^{16}$ However, the total economic cost due to CBPP 
in pastoral herds of Niger State, North-central Nigeria was estimated at US\$ 294,800.30. ${ }^{17}$

To shed light on these perspectives, this review examines the epidemiologic features of CBPP with emphasis on its causative agent, host, distribution, disease pathogenesis and pathology, and clinical manifestations in cattle herds. It also discusses the challenges and likely prospects associated with the diagnosis and control strategies in subSaharan Africa.

\section{Epidemiology}

\section{The Disease and Causative Agent}

CBPP is a severe infectious transboundary disease of cattle, caused by Mycoplasma mycoidess subspecies mycoides strain of the Class Mollicutes. ${ }^{1,18,20}$ It is characterized by fever, nasal discharge, cough, difficult respiration, severe edema, and proliferation of interstitial tissues in the lungs, diffused pneumonia, and serofibrionous pleurisy. $^{21}$ During epidemics, hyper-acute and acute forms of the disease predominate at the onset, while subacute and chronic clinical manifestations become more apparent as the epidemic progresses. ${ }^{22,23}$ For this reason and coupled with the fact that some infected animals could be carriers, it is sometimes difficult to detect clinical CBPP cases in endemic areas. ${ }^{24}$ When CBPP outbreak occurs in a susceptible cattle herd that has never been challenged by the disease, it causes up to $100 \%$ morbidity and nearly $50 \%$ mortality of the herd. ${ }^{25}$ The incubation period during natural infection is not known. ${ }^{26}$ Until the end of 2004, it was the only bacterial disease in the World Organization for Animal Health (OIE) 15 "List A" diseases, whose occurrence or re-occurrence in any member country must be reported to the organization within 24 hours, with weekly follow-up and 6-monthly evaluation. ${ }^{27}$ With the formation of the PACE in 1999, surveillance and reporting of CBPP in some African countries improved, but sadly declined after completion of the programme. ${ }^{28}$

Mycoplasmas belong to the class Mollicutes. Other members of this class are Ureaplasmas, Acholeplasmas, and Spiroplasmas. The Mycoplasmas cluster previously consisted of six closely related mycoplasmas which were made up of several ruminant pathogens, comprising of the following species or subspecies: Mycoplasma capricolum subsp. capricolum, M. capricolum subsp. capripneumoniae, M. mycoides subsp. capri, M. mycoides subsp. mycoides large-colony (LC), M. mycoides subsp. mycoides small-colony (SC), and Mycoplasma bovine biotype 7 now called M. leachii. M. mycoides subsp. capri, M. mycoides subsp. mycoides large-colony (LC), and M. mycoides subsp. mycoides small-colony (SC) are the best-known three species in the Mycoplasma mycoides cluster. However, M. mycoides subsp. mycoides large-colony (LC) is now considered as a serovar of $M$. mycoides subsp. capri and the nomenclature of $M$. mycoides subsp. mycoides small-colony (SC) has been changed to M. mycoides subsp. mycoides (Mmm). Therefore, Mmm now belongs to the classical $M$. mycoides cluster consisting of five pathogenic mycoplasmas: M. mycoides subsp. mycoides, $M$. mycoides subsp. capri, $M$. capricolum subsp. capricolum, M. capricolum subsp. capripneumoniae, and M. leachii, sharing many genotypic and phenotypic traits and causing diseases in ruminants. ${ }^{1,5,29}$

In 1995, Mmm was grouped into two epidemiogeograpghically distinct clusters: a cluster that contains strains isolated from different European countries, and another that contains African and Australian strains. ${ }^{30}$ Epidemiological and clinical investigations revealed that CBPP outbreaks of European origin are less virulent when compared with those observed in Africa. $\mathrm{Mmm}$ are pathogenic bacteria, with small sizes (500-1500 bp), lack a cell wall, are extremely fastidious in vitro, and form centre colonies on solid medium. Some $\mathrm{Mmm}$ are parasitic in nature, colonize the mucosal epithelium, and rely on the host for most nutritional requirements, while the majorities are commensals, but occasionally opportunistic, and invade lung tissues following other bacterial or viral infections. ${ }^{31,32}$ Mycoplasmas are resistant to antimicrobials that affect the cell walls and are also fragile to the environment due to the absence of cell walls. They have higher mutation rates than conventional bacteria, which indicates that they can rapidly develop resistance to antimicrobials, including oxytetracyclines and tylosin. $^{33,34}$

\section{Hosts and Transmission}

Under natural conditions, Bos indicus and Bos taurus cattle are susceptible to $\mathrm{Mmm}$, while there is variability in breed susceptibility in cattle, with trypanotolerant breeds more susceptible. ${ }^{35}$ Also, water buffaloes are susceptible to $\mathrm{Mmm}$, but it does not affect domestic buffaloes. ${ }^{35}$ CBPP has been reported in Asian yaks and American bison, but not in African buffaloes (Syncerus caffer). Sheep and goats are resistant to the disease. ${ }^{35}$

The epidemiology of CBPP has been characterized by direct transmission through contacts, a long incubation 
period, and likely early mycoplasma excretion during the course of the disease that takes up to 20 days before clinical manifestations and after recovery that takes up to 2 years in carriers (lungers). CBPP epidemiology in subSaharan Africa is dominated by different factors that include: disease occurrence in only cattle species, an absence of reservoir host in wildlife, and close contact transmission between susceptible cattle and infected ones. Also, uncontrolled movements of cattle play a significant role in CBPP maintenance in Africa. ${ }^{36}$ Disease transmission by close contact between the infected and susceptible cattle occurs almost exclusively when exhaled aerosols, especially those generated by cough, are inspired. ${ }^{37,38}$ Certain management practices that include kraaling (keeping cattle together in a small hut) at night and mixing of herds along stock routes and at watering points also promote CBPP transmission. The spread and impact of the disease is also favored by longdistance trekking of cattle along stock routes, as it provides opportunities for frequent contact of cattle within and between herds and the dust generated by mass movement increases pathogen spread. ${ }^{22}$ The nomadic culture and transhumance practice of the herdsmen have significantly contributed to the spread of CBPP in many African countries. ${ }^{39,40}$ With the isolation of $\mathrm{Mmm}$ from the foetus of an infected dam, trans-placental transmission has been indicated. ${ }^{41}$ Meanwhile, $\mathrm{Mmm}$ has been also isolated from the urine of an infected cattle in acute stages of CBPP, with titers ranging between 102 and $108 \mathrm{Mmm}$ per milliliter of urine. It has also been isolated from semen and sheath washings of two bulls. ${ }^{42,43}$ However, the significance of urine or semen in the natural transmission of Mmm is unknown, while transmission through fomites and contaminated fodder has been reported under experimental conditions. ${ }^{44}$ Outbreaks occur more extensively in cattle on transits, with the incubation period lasting from a few days to 6 months. In the susceptible cattle herds, the infection rate can be as high as $90 \%$ and the death rate can reach $50 \%$, and $25 \%$ of the infected cattle can recover and may become carriers, showing no clinical signs. The disease first came to Africa from Europe but its epidemiology in the later continent is still not well understood. ${ }^{16,45}$

Although water buffaloes are susceptible to CBPP, the mode of transmission of the disease from buffaloes to cattle is still unknown. Generally, $\mathrm{Mmm}$ has been epidemiologically described as specific for large ruminants, but has been also reported to be isolated from small ruminants. ${ }^{46}$ Two strains of Mmm (C305 and C425) have been isolated from caprine lungs, and three strains $(\mathrm{O} 326$, O512, and O526) have been isolated from ovine milk. Small ruminants can, therefore, serve as potential reservoirs for $\mathrm{Mmm}$ and need to be considered in the surveillance and control programme for CBPP in Africa. ${ }^{46,47}$

\section{CBPP Distribution in Africa}

Except in South America and Madagascar, the occurrence of CBPP has taken place at some times worldwide. ${ }^{23}$ The disease is endemic in most of the pastoral cattle herds of Western, Central, and Eastern Africa, Angola, and Northern Namibia. ${ }^{48}$ Cattle herds in East, Central, and West Africa are believed to have been infected by cattle traded from India in the 19th century. ${ }^{49}$ Although CBPP was eradicated from the US and Great Britain in the 19th century, it still persists in many African countries, and was widespread in 12 countries in Africa between 2007 and 2008..$^{50,52}$

In the 1980s, the geographical distribution of CBPP was limited and almost no outbreaks were observed due to annual combined vaccination campaigns from the efforts toward the control of Rinderpest. The disease gained a wider extension in Africa in the 1990s as it re-invaded countries such as Botswana, Tanzania, and Rwanda that had eliminated it in the past. However, Botswana succeeded in regaining a free status after very strict sanitary measures. The incidence of CBPP is increasing in many countries of Africa and had been reported in at least 27 countries in equatorial, central, and southern Africa by the end of $1999 .{ }^{53,54}$

In 2015, CBPP was considered to be present in all subSaharan African countries. The Southern part of the continent is still considered to be free of the disease due to the physical barriers that prevent its spread, such as the Namibian veterinary cordon fence, but the Southern African Development Community (SADC) countries are clearly still at risk (Figure 1). Most cattle herds in subSahara African countries are infected with $\mathrm{Mmm}$, except such countries as Senegal and Gambia in West Africa, and Gabon and Congo Brazzaville in Central Africa that do not report the disease. ${ }^{54}$

Since 2006, 18 countries in the west, central, east, and southern regions of Africa, except Congo DR, and Gabon, have been reporting CBPP to the African Union InterAfrican Bureau for Animal Resources (AU-IBAR). However, DRC and Gabon started reporting in 2010. In countries that reported the disease, 304 epidemiological units were affected by the disease, involving 16,836 cases and 3007 deaths, with an estimated case fatality rate of 


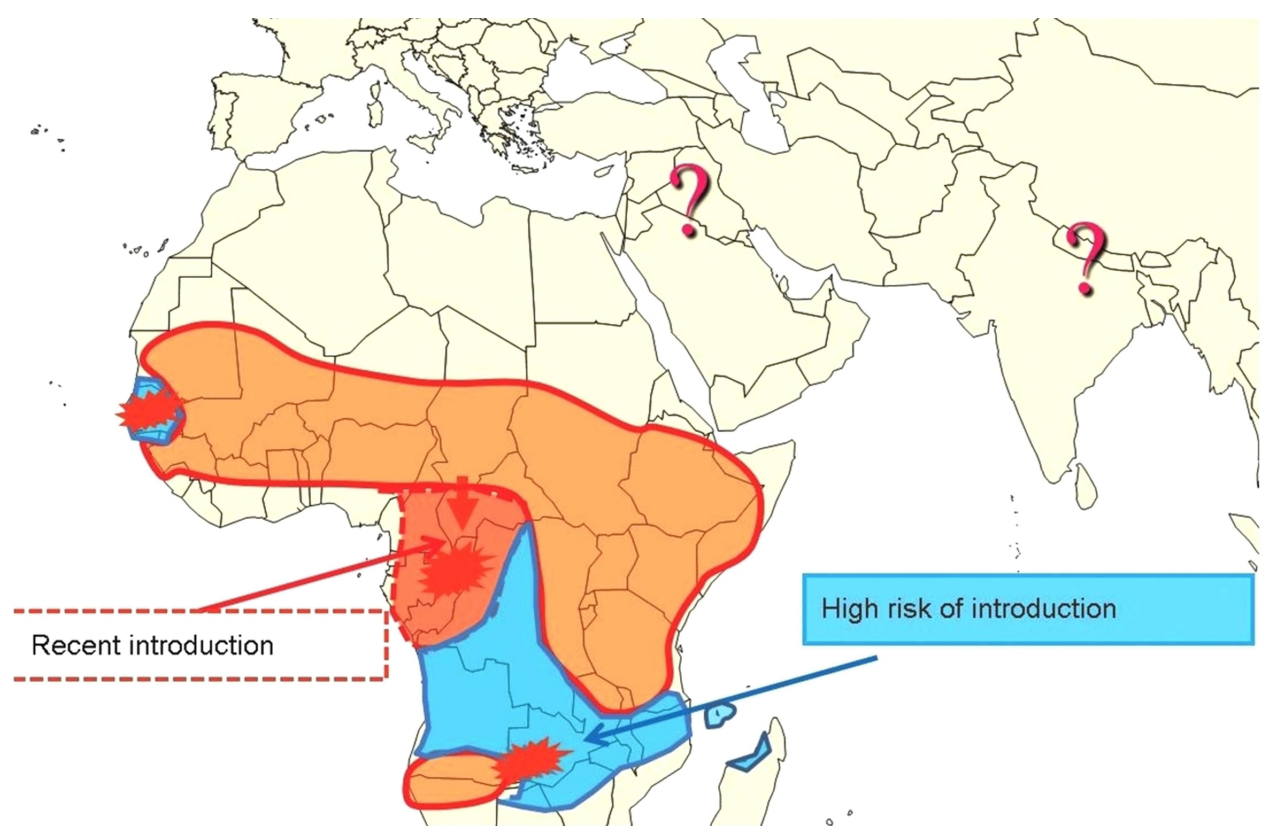

Figure I Distribution of CBPP and risks of introduction in southern areas of Africa.

Notes: Reproduced with permission from FAO, 2016, Can contagious bovine pleuropneumonia (CBPP) be eradicated? http://www.fao.org/3/a-i6/26e.pdf. ${ }^{54}$

$17.9 \%$. The highest number of CBPP outbreaks was reported in Ghana (75) followed by Central African Republic (43) and Ethiopia (29) (Table 1). CBPP is endemic in most of the West, Central, and East African countries, with at least 24 countries (45\%) regularly reporting outbreaks every year for a 10 years period (Figure 2). The disease is also encroaching on new areas with The Gambia reporting an outbreak in 2013 for the first time after being free of the disease for 45 years. CBPP has now also been reported in a few countries in Southern Africa (Angola, Namibia, and Zambia). The reported morbidity and mortality as well as case fatality rates have been variable and

Table I Countries in Sub-Saharan Africa Reporting CBPP to the AU-IBAR

\begin{tabular}{|c|c|c|c|c|c|}
\hline Country & Outbreaks & Cases & Deaths & Slaughtered & Destroyed \\
\hline Burkina Faso & 4 & 203 & 45 & 0 & 0 \\
\hline Cameroon & 8 & 384 & 16 & 41 & 0 \\
\hline Central African Republic & 43 & 3674 & 1270 & 0 & 0 \\
\hline Chad & 17 & 342 & 200 & 37 & 18 \\
\hline Congo, DRC & 15 & 8277 & 458 & $|36|$ & 0 \\
\hline Cote d'Ivoire & 18 & 595 & 215 & 13 & 7 \\
\hline Ethiopia & 29 & 457 & 112 & 12 & 0 \\
\hline Gabon & 3 & 0 & 0 & 0 & 0 \\
\hline Ghana & 75 & 127 & I & 115 & 0 \\
\hline Mali & 4 & 204 & 82 & 119 & 0 \\
\hline Niger & 6 & $4 I$ & 10 & 0 & 0 \\
\hline Nigeria & 22 & 489 & 96 & 221 & 9 \\
\hline Somalia & 12 & 69 & 16 & 0 & 0 \\
\hline Sudan & 2 & 202 & 92 & 108 & 0 \\
\hline Tanzania & 8 & 399 & 177 & 0 & 0 \\
\hline Togo & 9 & 13 & 3 & I & 0 \\
\hline Uganda & 22 & 1330 & 193 & 67 & 0 \\
\hline Zambia & 7 & 30 & 21 & 0 & 1 \\
\hline Total & 304 & 16,836 & 3007 & 2095 & 35 \\
\hline
\end{tabular}

Note: Reproduced with permission from AU-IBAR. ${ }^{55}$ 


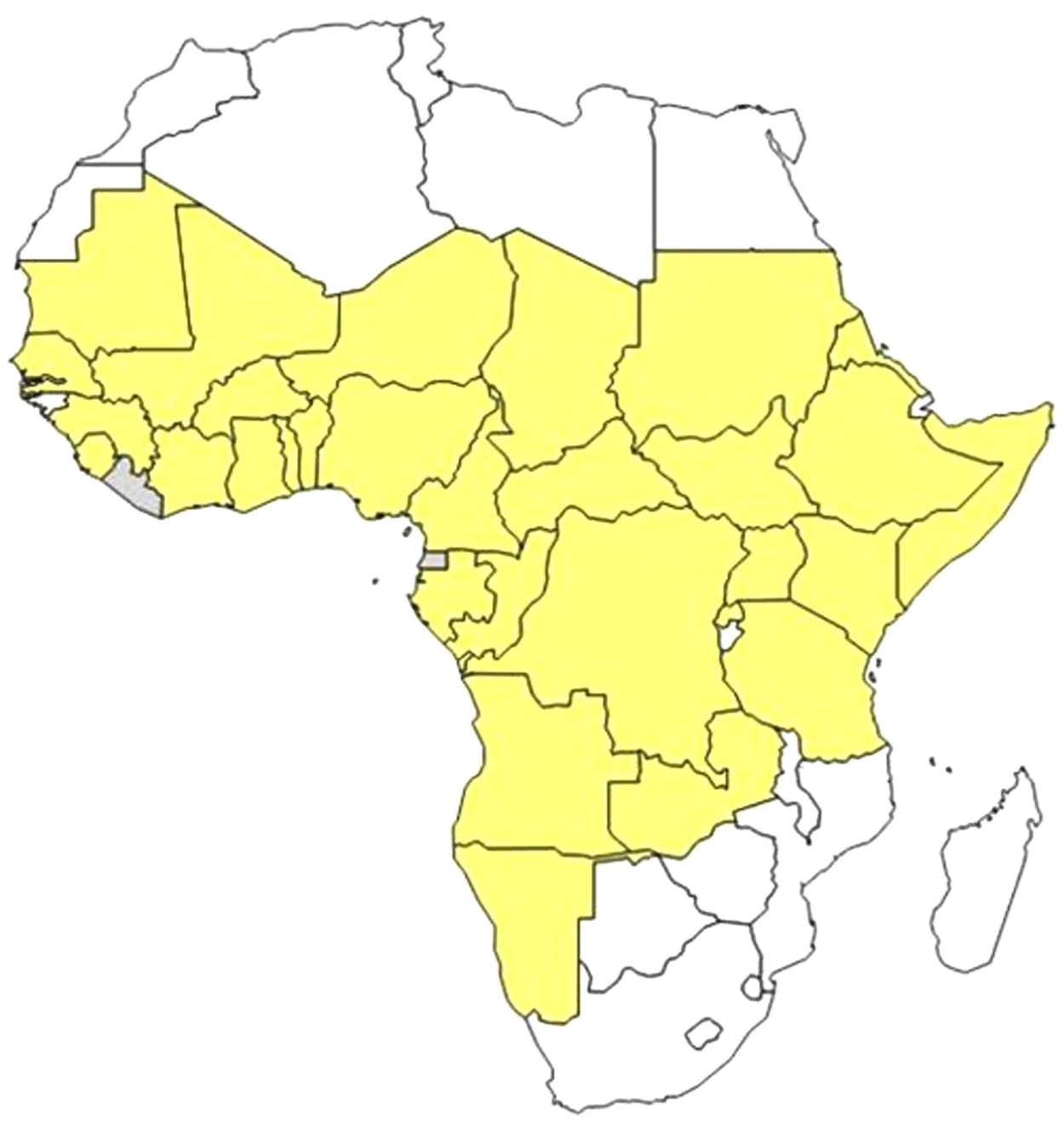

Figure 2 CBPP affected countries in Africa: 2004-2014. Source:

Notes: Reproduced with permission from FAO, 2016, Can contagious bovine pleuropneumonia (CBPP) be eradicated? http://www.fao.org/3/a-i6/26e.pdf. ${ }^{54}$

there appears to be no clear seasonal pattern to the outbreaks. $^{55}$

The occurrence and distribution of CBPP in cattle herds is influenced by many intrinsic and extrinsic factors that include intermittent infections, age, genetic constitution, crowding, climatic conditions, and stress from transportation, and handling. These importantly determine the final outcome of $\mathrm{Mmm}$ infection in herds. ${ }^{56}$

\section{Pathogenesis and Pathology}

The pathogenesis of CBPP in susceptible animals is characterized by the development of thrombosis in the pulmonary vessels, which may occur prior to the establishment of pneumonic lesions. The process of thrombosis formation is not well known, but partly believed to be mediated by induction of cytokines. ${ }^{57}$ The disease causes a variety of pneumonia in the lung lobes, with prominent dilated inter- lobular septa resulting from high out-pouring of plasma and fibrin in them, giving a "marbling" effect to the lung. ${ }^{51}$ The characteristic inflammatory reactions led to bronchitis, bronchiolitis, and alveolitis, while neutrophils and mononuclear cellular response predominantly constitute early inflammation in Mycoplasma pneumonia. Pathologically, CBPP causes unilateral pulmonary necrosis, marked serosanguineous fluid accumulation in the interstitia and pleura, and sometimes sequestration. ${ }^{54}$ An important component of the pathological changes is vasculitis, which indicates marked exudation and pleurisy. Thrombosis can cause ischemic necrosis and infarcts of the lung. Anoxia and toxaemia can lead to death of the affected cattle. ${ }^{58}$

Mollicutes produced some substances that are very vital in the pathogenesis of CBPP. They produce peroxide and super-oxide that may cause disruption of host cell integrity. Ureaplasma species produce urease that may 
cause injury to host tissues due to an effect of ammonia produced from urea hydrolysis. Mycoplasma phospholipases, potentially important in pneumonia, may reduce surface tension of the alveolar surfactants, thereby causing atelectasis. $\mathrm{Mmm}$ has a galactan polymer that modulates the immune response and promotes its dissemination. ${ }^{51}$

\section{Clinical Manifestations}

CBPP is manifested in four forms: hyperacute, acute, subacute, and chronic forms. The hyperacute form is seen at the onset of the disease outbreaks, may affect up to $10 \%$ of the infected herd, and sudden death occurs often without other clinical signs. About $20 \%$ of the affected cattle are observed during the acute form, with the course usually running from 5 to 7 days, and characterized by fever, self isolation from the herd, anorexia, and difficult breathing that is labored and painful. Other signs that may be observed include abdominal breathing and "grunting" during expiration. Affected cattle may develop a shallow, dry, and painful cough that is often observed during exercise. Affected animals may protest when pressure is applied between the ribs because of pain and could sometimes react violently. ${ }^{59}$ Also, affected animals in acute form stand with nostrils dilated, mouth open, and panting for air, head, and neck extended, forelegs spread apart, frothy saliva accumulation in and around the mouth, and nasal discharge, sometimes streaked with blood. Furthermore, some affected animals may develop swellings of the throat and dewlap in this stage. About $40 \%$ to $50 \%$ of the affected cattle are most frequently seen in subacute form with characteristic signs resembling those in the acute form, though they could be less severe and with recurrent fever. Some cattle may directly go into the chronic stage, which is a natural evolution of both acute and subacute stages. The clinical manifestations gradually regress, though affected cattle may still manifest fever, anorexia, and loss of weight. Young calves often manifest swollen, hot, and painful limb joints that result in lameness. ${ }^{48,59}$

\section{Diagnosis}

Diagnosis of CBPP relies on clinical examinations, postmortem inspections, and laboratory analyses through culture and isolation procedures, and serological analyses. Protein and nucleic acid-based molecular techniques have also evolved and are more specific. ${ }^{20,42,60}$

\section{Clinical Examinations}

When first introduced into a herd that has not been previously challenged with the disease, it causes high deaths of cattle.
Few of them may die rapidly showing signs of only fever. However, clinical signs start manifesting several days to months after $\mathrm{Mmm}$ infection, indicating that the disease can occur in a herd long before clinical signs are manifested, which makes tracing back difficult especially where there is a long interval practice between vaccination campaigns, and where antimicrobials are often used to manage clinical cases. ${ }^{59}$

The use of clinical signs for the diagnosis of CBPP in pastoral herds in Africa is generally more feasible in the acute stage of the disease when symptoms are apparent, with adult cattle showing persistent cough and respiratory distress due to pleuropneumonia, and calves show lameness due to arthritis. $^{48,59}$ The severity of manifested signs declined proportionally to the duration of the disease presence in the herd. All mentioned clinical signs are not pathognomonic to CBPP. It is, therefore, important during clinical diagnosis to rule out other differential diseases that could present similar clinical manifestations such as acute pasteurellosis, hemorrhagic septicemia, actinobacillosis, bovine tuberculosis, abscesses or hydatid cysts, or traumatic pericarditis from the differential diagnosis. 59

\section{Post-Mortem Examinations}

Post-mortem examinations often show gross pathological lesions, such as sequestra, which are encapsulated necrotic pulmonary lesions. In the acute stage, gross pathological lesions in the lungs are characterized by fibrinous deposits on the parietal surfaces and interlobular spaces distension due to accumulation of straw coloured serofibrinous exudates. $^{51,61}$ Pathological lesions commonly affect one lung and are often localized in the diaphragmatic lobe with a characteristic marbling appearance, while the pleural cavity may contain large quantities of clear, yellow-brown fluid with pieces of fibrin. ${ }^{25}$

On palpation, lesions can be detected while red and grey areas of hepatisation are seen upon incision. Gross lesions are characterized by formation of necrosis in the lobules and interlobular septa and early sequestrum formation are seen in subacute cases. Gross lesions in chronic cases are characterized by well-defined sequestra surrounded by fibrous capsules, and adhesions, which are connecting thickened viscera and parietal pleura. ${ }^{59,62}$

\section{Serological Analysis}

The Complement Fixation Test (CFT) and competitive Enzyme Linked Immunosorbent Assay (c-ELISA) are serological tests recommended by the OIE for herd-level serological diagnosis and are commonly used for the 
disease investigation in Africa. The CFT sensitivity to $\mathrm{Mmm}$ infection vary with the clinical stage of CBPP manifestation, which is high in acute stage due to the high level of circulating complement fixing immunoglobulin. ${ }^{18,40,54,62}$ A sensitivity of $98 \%$ has been reported in a study on CBPP outbreaks in Botswana with post mortem lung lesions used as a gold standard. ${ }^{62}$ However, a lower sensitivity of $64 \%$ has been observed from a study conducted elsewhere in Italy, where the disease had very low prevalence due to an eradication programme. $^{63}$

A c-ELISA using a specific monoclonal antibody targeting $\mathrm{Mmm}$ antigens have been used in many herds in Africa. $^{20,40}$ Cross-reactions with other Mycoplasma species were not reported, while $96 \%$ sensitivity and $97 \%$ specificity were observed. ${ }^{20,64}$

Immune responses development detected by both CFT and c-ELISA have been observed in cattle vaccinated with live attenuated CBPP vaccine. ${ }^{65,66}$ However, sero-prevalence studies on vaccinated cattle herds in some African countries have shown poor agreement between CFT and c-ELISA. ${ }^{67}$ Attempts to apply serological techniques to assess the efficiency of vaccination in cattle vaccinated against the disease have not been successful, because vaccination that involves use of T1/ 44 or T1-SR vaccine strains does not always induce detectable antibody responses. It is, therefore, not advisable to use only CFT or cELISA to monitor the efficiency of a vaccination. It is, therefore, noteworthy that CFT or c-ELISA can be used to detect natural infections in cattle herds in Africa even in the areas where a vaccination campaign has not been regularly conducted because post-vaccination antibodies do not persist after 3 months. Both tests are useful only in the diagnosis of the disease in herds and not for individual infected cattle. ${ }^{66,68}$

A $48 \mathrm{kDa}$ protein has identified field strains of $\mathrm{Mmm}$ in Europe, Africa, and Australia and is named LppQ. The protein has been applied in the detection of $\mathrm{Mmm}$ in experimentally infected cattle using Immunoblotting test and could be used also for the diagnosis of CBPP under natural conditions in Africa. ${ }^{69}$

\section{Molecular Analyses}

Mycoplasmas, including $\mathrm{Mmm}$, have been traditionally isolated by biochemical and antigenic techniques using culture and identification. ${ }^{70,71}$ These techniques have been limited by their low sensitivity and specificity due to cross-reactivity of antigenic determinants of closely related species, bacterial contamination, and time and labour intensive laboratory procedures. With the introduction of polymerase chain reaction
(PCR) in 1994, considerable improvements have been made because it has provided a quicker and more sensitive diagnosis of CBPP. ${ }^{72,74}$ However, identification of $\mathrm{Mmm}$ has been problematic because of the close phylogenetic relatedness between it and other members of the $M$. mycoides cluster that include $M$. mycoides subsp. mycoides biotype large colony (now serovar of $M$. mycoides subsp. capri), M. mycoides subsp. capri, M. capricolum subsp. capricolum, M. capricolum subsp. capripneumoniae, and M. leachii. Also, there have been difficulties in the identification of $\mathrm{Mmm}$ and other members of the "mycoides cluster", which was due to shared genetic, immunologic, and biochemical characteristics. $^{74,76}$ These are some of the challenges encountered by molecular laboratories in Africa.

The challenges notwithstanding, PCR has provided powerful diagnostic procedures for the specific identification of Mmm strains, as well as robust fast detection, identification, and differentiation of members of the $M$. mycoides cluster. $^{72,74,77,79}$ Of particular interest is the use of nested PCR systems that are sensitive for the detection of $\mathrm{Mmm}$ in cultures and clinical materials with very low numbers of target organism. $^{74,80}$

Studies on the molecular epidemiology of $\mathrm{Mmm}$ have indicated that there are three lineages of $\mathrm{Mmm}$ in Africa, and these are the African, Australian, and European lineages. ${ }^{75,81}$ An important element, insertion sequence IS1296, has eased the earlier difficulty associated with species differentiation. ${ }^{82,83}$ In an investigation that involves the use of a DNA probe against IS element, distinct strains of the African and Australian, and European origins within $\mathrm{Mmm}$ subspecies were identified. ${ }^{82}$ It has been identified that the variability in the two strains was due to a lack of $8.84-\mathrm{kb}$ deletion in European strains but present in strains of African and Australian origins. ${ }^{30}$ The insertion of IS1296 upstream of this deletion area was considered stable enough for species typing, and thence applied as a molecular marker in the restriction fragment length polymorphism (RFLP) analysis of strains of $M m m .{ }^{84,85}$ Furthermore, the location of this maker has been used for the development of PCR assay that specifically identified and differentiated $\mathrm{Mmm}$ of these geographical backgrounds. ${ }^{82}$

Insertion sequences (ISs), which are useful molecular markers for the diagnosis and epidemiological studies of bacterial pathogens, can cause large genomic rearrangements in bacteria, such as deletions, insertions, and inversions. IS elements are mobile DNA segments that are less than $2.5 \mathrm{~kb}$, with structural and organizational similarities. They possess one or two Open Reading Frames (ORFs), 
and on rare occasions three or more. ${ }^{84}$ These genes encode proteins required for the transposition of IS elements, such as a transposase. The termini of IS elements normally form inverted repeats (IRs), which is the recognition and cleavage sites of the IS-encoded transposase, in the transposition reactions. ${ }^{84}$ Only two IS elements have been attributed to $\mathrm{Mmm}$, the IS1296 and IS1634. ${ }^{86,87}$ During IS typing with an IS1296-specific probe, Mmm strains were clustered into two major epidemiologically distinct geographical groups. ${ }^{83,85}$

\section{Participatory Epidemiology}

Pastoral communities in Africa are mostly found in underdeveloped and hard-to-reach environments. Surveillance and research of CBPP and other livestock diseases in these locations are very hard to carry out because the human populations are small, highly mobile, and move with their livestock across large grazing areas that have few means of modern communication. ${ }^{88}$ Also, most of the pastoralists live in transboundary ecosystems and traverse across international borders for transhumance and nomadic grazing. Conventional approaches to surveillance and research of diseases in such circumstances need considerable flexibility, commitment, and resources. With constraints of resources in these socioeconomic disadvantage communities, pastoralists themselves become more valuable sources of information on livestock diseases. ${ }^{89}$ One useful approach for disease identification in rural hard-to-reach areas of Africa is by the use of Participatory Epidemiology (PE) techniques. ${ }^{90,91}$

PE uses participatory techniques for research and surveillance of diseases in rural settings. As a proven approach, it can be used to overcome many of the limitations associated with conventional research and surveillance methods, and has been used to solve a number of animal health issues. ${ }^{89,92,93}$ It uses participatory rural appraisal (PRA) tools to collect qualitative epidemiological data or intelligence information possessed by the communities through observations, existing knowledge, and traditional oral history to improve on the understanding of animal health issues. ${ }^{94}$ PRA tools are a range of techniques that allow for collection and analysis of data through learning and facilitation platforms that enable local people to play a role in defining, analyzing, and solving their socio-economic problems, that is, collection of epidemiological data and their transformation to information. ${ }^{95}$

PE uses local knowledge for disease identification and control programmes, which have been both effective and acceptable to the stakeholders. ${ }^{92}$ Since PE recognizes local people to be very rich in detailed traditional knowledge and vocabulary about infectious diseases that affect their socio-economic livelihoods and well-being, it can be used for adequate description of clinical presentations and epidemiological patterns as well as identification of main pathological lesions of CBPP in hard-to-reach pastoral cattle herds environments in Africa and other developing countries.

\section{Control Strategies}

Four essential control approaches that include vaccination, treatment, movement control, and stamping-out through slaughter with compensation have been adopted towards mitigation of CBPP in Africa. ${ }^{2}$ Each of these mitigation measures reduces the occurrence of the effective reproductive number $\left(\mathrm{R}_{\mathrm{o}}\right)$ of $M m m$ in cattle populations. ${ }^{2}$ Unfortunately, most of the CBPP affected countries in Africa do not apply all of these measures at the same time due to technical and logistic reasons. However, the AU-IBAR advocated a policy for control of the disease in Africa, which includes epidemiological data and information collection to identify foci of CBBP occurrence through active surveillance, regular annual mass vaccination of cattle herds two intervals in a year for at least 5 consecutive years with attainment of herd immunity, and effective movement control from and towards the infected foci. ${ }^{34}$ Application of a mass vaccination campaign to vaccinate all herds in endemic areas two times in a year for 5 years implies close to $100 \%$ vaccination coverage and concurrent application of movement control will effectively mitigate the menace of the disease in Africa. ${ }^{2}$

In many areas endemic with the disease, managing it has been challenging, mostly due to a lack of animal identification systems and difficulty in animal movement restriction and control. CBPP vaccination campaigns have been carried out in many African countries using T1/44 vaccine. Although it is the most commonly used vaccine, it does not confer $100 \%$ immunity and conferred immunity only lasted for a short period of 6 months and can induce severe adverse reactions. ${ }^{96}$ Notwithstanding the low efficacy of this vaccine as well as the low vaccination coverage in many herds, it still remains the most widely used vaccine for the control of the disease in Africa ${ }^{26}$ CBPP vaccination is mostly based on the inoculation of freeze-dried live attenuated $\mathrm{Mmm}$ T1/44 vaccine. ${ }^{97,98}$ There is also a streptomycin resistant variant (T1/sr) vaccine that was used in combination with rinderpest vaccine during the rinderpest campaign. ${ }^{98}$ As previously indicated, this approach was very successful for rinderpest eradication in Africa but not for CBPP as its occurrence still persists. Despite the application of vaccine that contains a minimum dose of 107 viable $\mathrm{Mmm}$ per 
dose, as recommended by the OIE, for vaccinated susceptible cattle to be induced adequate immunity against the infection, CBPP still persists in Africa due to earlier mentioned limitations. $^{20,97}$

The use of antimicrobials for the management of clinical cases of CBPP is a standard field practice in many cattle herds in Africa. Pastoralists and veterinarians practicing in the field have attested to the beneficiary effects of treatment with antimicrobials. Control of CBPP using antimicrobials has been reported to reduce the impact of CBPP in affected cattle population cattle. ${ }^{2}$ Studies have shown that when antimicrobials are used on an infected cattle herd, they reduce the $\mathrm{Mmm}$ infection rate by $50 \%$ while the mortality rate is reduced by $64 \%$, and prevalence is also reduced from $75.4 \%$ to $33.2 \%$. ${ }^{99}$ Therefore, use of an appropriate treatment regime can reduce effects of CBPP by at least half. Although widely used, antimicrobial treatment against CBPP is still not an official practice of the control of CBPP because of the suspicion that it may increase development of $\mathrm{Mmm}$ resistant strains, mask clinical disease occurrence, promote formation of sequestra, and increase the number of carrier cattle in herds. ${ }^{48}$ The presence of infected cattle with masked CBPP clinical signs in herds makes disease diagnosis difficult, making infections in herds unrecognized and promoting $\mathrm{Mmm}$ transmission. Antimicrobials are still widely used by the pastoralists to manage CBPP in Africa, and studies have also demonstrated the usefulness of antimicrobials against the disease in both invivo and in-vitro studies. ${ }^{34,38,100,103}$ In a clinical trial, longacting tetracycline has been shown to be effective in reducing the clinical severity of the disease in affected cattle but ineffective in the prevention of viable $\mathrm{Mmm}$. Although the direct impact of tetracycline on individual treated cattle was encouraging as clinical damage was reduced, the indirect effect observed on the population was not, because clinical signs of the disease were masked. ${ }^{102,104}$

The use of antimicrobials for control of CBPP in affected cattle herds in endemic areas is theoretically prohibited due to the lack of antimicrobial efficacy against the disease clinically. However, antimicrobials are still widely used by herders and professionals in the field in Africa. Though antimicrobials usage may greatly reduce transmission of $\mathrm{Mmm}$ to healthy ones, adequate mitigation against the disease can be achieved through concurrent application of antimicrobial treatment with vaccination. ${ }^{103,105}$ Nevertheless, the use of marbofloxacin and spiramycin groups has been fruitful in the treatment of contagious caprine pleuropneumonia (CCPP), a similar disease in sheep and goats, as they produced a higher (70\%) curative rate than the oxytetracycline group (40\%) and a lower fatality rate $(30 \%)$ than the oxytetracycline group $(60 \%){ }^{106}$ This treatment regiment can be used for CBPP mitigation in endemic herds.

Control of CBPP by movement control and stamping-out could not be effectively adopted in many countries in Africa because the measures are too costly and logistically difficult, while many of them are faced with limited financial resources. Vaccination and treatment are still the better alternatives and possibilities for CBPP control in Africa. ${ }^{2,107}$ CBPP was eradicated through stamping-out and strict animal movement control in the US, Japan, and Western Europe, ${ }^{8,48}$ but not successfully practiced in most African countries. It is important to note that stamping-out was successfully applied to control the disease in Botswana. ${ }^{108}$ Unfortunately, stamping-out may not be practicable in most of the CBPP endemic countries in sub-Saharan Africa because of its capital intensive nature, and vaccination remains the most effective control strategy. Nevertheless, vaccination can only be successful and effective if it is repeated at regular short intervals of 6 months for 2 years, and annual coverage for $3-5$ years consecutively. ${ }^{56,66}$

\section{Immunity Against Mmm Infections}

The use of attenuated T1/44 live strain for vaccination remains the most effective method of choice for the control of CBPP since stamping-out and movement control are difficult to implement by most disease endemic countries in Africa. Field observations have indicated that naturally recovered cattle develop immunity against Mmm but may be re-infected. However, no information is available on the understanding of what is meant by "infected and recovered" cattle in herds. ${ }^{109}$

Although the widely used T1/44 attenuated live vaccine has been known to provide immunity for up to 1 year, it cannot prevent formation of gross pathological lesions in challenged animals, which indicates that it only induces limited immunity. ${ }^{110}$ However, no study has reported $\mathrm{Mmm}$ infections to induce solid immunity continuously in infected cattle. The main protective mechanism against the disease in the immunology of CBPP is not understood. ${ }^{41}$ Although the actual nature of the protective response against $\mathrm{Mmm}$ is still under investigation, there is a postulation that describes involvement of immune responses in protection against $\mathrm{Mmm}$ during a primary infection and is thought to contribute to a reduction in disease severity because of the available acquired immunity induced after vaccination. ${ }^{23,111}$

Many studies have described the role of CD4+ T-cells in the protection of animals against $\mathrm{Mmm}$ during its primary 
infection. ${ }^{112,113}$ A correlation between high numbers of mycoplasma-specific IFN $\gamma$ secreting CD4+ T lymphocyte subsets and a mild form of the disease during primary infection has been observed. ${ }^{112,114,116}$ However, CD4+ T-cells protective role against $\mathrm{Mmm}$ in vaccinated cattle is still under contest. ${ }^{117}$ IFN $\gamma$, a cytokine, is produced mainly by natural killer and natural killer T-cells as part of the innate immune response and by CD4 Th1 and CD8 cytotoxic T lymphocyte effector T-cells when antigen-specific immunity develops. ${ }^{118}$ It plays an important role in innate and adaptive immunity against viral and intracellular bacterial infections, and activates macrophages that possess aberrant expressions associated with autoinflammatory and autoimmune diseases that have immunostimulatory and immunomodulatory effects. ${ }^{119}$ To provide evidence for a protective role of IFN $\gamma$ secreting CD4+ T-cells, a study has reported that total depletion of CD4+ T-cells in infected animals has led to a dramatic increase in CBPP severity and mortality during $\mathrm{Mmm}$ primary infection. ${ }^{118}$

Ascribing protection of infected cattle to high antibody titers against $\mathrm{Mmm}$ during primary infection will be difficult, since no readily available study has reported direct correlation between antibody titers and disease severity in infected animals. The only assumption was that innate responses could play an important role in the protection. However, there are studies that have reported the protective role of CD4+ T-cells against $\mathrm{Mmm}$ in combination with antibody production after vaccination or during secondary infection. ${ }^{113}$ Since CBPP occurrence in naïve herds is often associated with very high mortality, there is an indication that the induced immune responses are not sufficient or may be too late to adequately protect against the infection. All these assertions indicate that CD4+ T-cells driven acquired responses play a minor defensive role against primary $\mathrm{Mmm}$ infection. ${ }^{117}$ Furthermore, the poor immunity protection provided after vaccination with live T1/44 attenuated vaccine could be correlated with the low cell mediated immune response elicited during the infection. ${ }^{119}$ Therefore, the role of innate, acquired cell mediated, and humoral immunity in conferring protection in $\mathrm{Mmm}$ infected cattle is still under investigation. However, the pathological lesions caused by $\mathrm{Mmm}$ infection, even after vaccination, are important indications of an immunopathological process. ${ }^{120}$

In the final note, the diagnosis of CBPP should be based on both the presence of its lesions and demonstration of $\mathrm{Mmm}$ in infected tissues and serological tests be used at the herd level for herd immunity assessment. CBPP control in sub-Saharan Africa is still constrained by several factors that include deterioration of quality veterinary services and paucity of financial resources for diagnostic and sustained control programmes, as well as the absence of policies on cattle movement control within and between countries. These problems have promoted dissemination of the disease in most parts of Africa. However, effective CBPP control in Africa is achievable, but only through stronger political commitments that will prioritize the disease among major diseases of very high economic importance to the continent's livestock industry. CBPP endemic countries should convince regional organizations, international bodies, and funding partners to invest in CBPP control as a basis for improving food security, livelihoods, and the general wellbeing of people.

\section{Conclusions}

Contagious bovine pleuropneumonia presently poses a series of challenges to livestock industry and socioeconomic welfare of pastoralists in sub-Saharan Africa. These challenges cover not only the epidemiological features but also several important methodological gaps that concern the diagnostic tools and control strategies. As outlined above, serological tests and molecular methods are available for diagnosis, but a little bit complex and expensive. There is a need to make available simpler and more rapid field tests that can be effectively and efficiently used to provide highly sensitive and specific results in the field. Many countries in Africa do not have the capacity to provide manpower and facilities for mitigation of infectious animal diseases emergence, such as CBPP, due to inadequate infrastructures, limited financial resources, non-functional animal health establishments, terrorisms, and social conflicts that affect pastoralists. In some countries, status of current CBPP prevalence is not known due to the absence of active surveillance and disease outbreaks reporting. Effective control of the disease in Africa can be, therefore, achieved if primary endemic areas and predisposing factors influencing its occurrence are fully investigated. Addressing these challenges will assist in the design and implementation of diagnostic and control strategies that will mitigate the disease dynamic in the continent. Also, the use of Participatory Epidemiology, in conjunction with the conventional diagnostic tools, will improve identification of CBPP in hard-toreach pastoral rural communities, promote control of the disease, and assure food security in Africa.

\section{Acknowledgment}

The authors are grateful to Dr. Ismail A. Odetokun for logistical inputs in the manuscript. 


\section{Disclosure}

The authors report no conflicts of interest in this work.

\section{References}

1. Manso-Silván L, Vilei EM, Sachse K, Djordjevic SP, Thiaucourt F, Frey J. Proposal to assign Mycoplasma leachii sp. nov. as a new species designation for Mycoplasma sp. bovine group 7 of leach, and reclassification of Mycoplasma mycoides subsp. mycoides LC as a serovar of Mycoplasma mycoides subsp. capri. Int J Syst Evol Microbiol. 2009;59(6):1353-1358. doi:10.1099/ijs.0.005546-0

2. Tambi NE, Maina WO, Ndi C. An estimation of the economic impact of contagious bovine pleuropneumonia in Africa. Rev Sci Tech. 2006;25(3):999-1012. doi:10.20506/rst.25.3.1710

3. Vilei EM, Frey J. Detection of Mycoplasma mycoides subsp. mycoides $\mathrm{SC}$ in bronchoalveolar lavage fluids of cows based on a TaqMan real-time PCR discriminating wild type strains from an lppQ(-) mutant vaccine strain used for DIVA-strategies. $J$ Microbiol Methods. 2010;81(3):211-218. doi:10.1016/j.mimet.2010.03.025

4. Ajuwape ATP, Ikheloa JO, Ojo MO, Alaka OO, Adetosoye AI. Biochemical and serological identification of Mycoplasma isolated from pneumonic bovine lungs in Nigeria. Israel J Vet Med. 2003;58:2-3.

5. Fischer A, Shapiro B, Muriuki C, et al. The origin of the 'Mycoplasma mycoides cluster' coincides with domestication of ruminants. PLoS One. 2012;7(4):e36150. doi:10.1371/journal. pone. 0036150

6. OIE. Final Report of the 17th Conference of the OIE (World Organization for Animal Health) Regional Commission for Africa: strategy for strengthening epidemiological surveillance in Africa, Asmara, Eritrea, 26 February - 1 March; OIE, Paris; 2007:53-54.

7. Windsor RS. The eradication of contagious bovine pleuropneumonia from south western Africa: a plan for action. Ann NY Acad Sci. 2000;916:326-328. doi:10.1111/j.1749-6632.2000.tb05309.x

8. Masiga WN, Domenech J. Overview and epidemiology of contagious bovine pleuropneumonia in Africa. Rev Sci Tech. 1995;14:611-630. doi:10.20506/rst.14.3.869

9. Thiaucourt F Status of contagious bovine pleuropneumonia (CBPP) in Nigeria with emphasis on control strategies. FAOOIE-AU/IBAR-IAEA Consultative Group Meeting on CBPP in Africa. 12-14 November; Rome, Italy; 2003.

10. Thomson GR Contagious bovine pleuropneumonia and poverty: A strategy for addressing the effects of the disease in sub-Saharan Africa. Research Report. DFID Animal Health Programme. Centre for Tropical Veterinary Medicine, University of Edinburg, UK; 2005.

11. Waite ER, March JB. The effect of HEPES buffer systems upon the $\mathrm{pH}$, growth and survival of Mycoplasma mycoides subsp. mycoides small colony $(\mathrm{MmmSC})$ vaccine cultures. FEMS Microbiol Lett. 2001;201:291-294. doi:10.1111/j.15746968.2001.tb10771.x

12. Mariner JC The dynamics of CBPP endemism and the development of effective control/eradication strategies for pastoral communities: final modeling report. Project GCP/RAF/365/EC. Food and Agriculture Organization of the United Nations; 2003.

13. Alhaji NB, Babalobi OO. Socio-cultural factors influencing transmission of Mycoplasma mycoides mycoides small colony in pastoral cattle herds of north-central Nigeria. Vom J Vet Sci. 2015;10 (1):1-13.

14. Windsor RS, Wood A. Contagious bovine pleuropneumonia. The costs of control in central/southern Africa. Ann NY Acad Sci. 1998;849:299-306. doi:10.1111/j.1749-6632.1998.tb11062.x
15. Masiga WN, Rossiter P, Bessin B Present situation of CBPP in Africa and epidemiological trends. Report of the first meeting of the FAO/OIE/OAU/IBAR Consultative Group on Contagious Bovine Pleuropneumonia, 5-7 October, Rome, FAO; Rome, Italy; 1998:25-31

16. Egwu GO, Nicholas RAJ, Ameh JA, Bashiruddin JB. Contagious Bovine Pleuropneumonia: an update. Vet Bull. 1996;66:876-888.

17. Alhaji NB, Babalobi OO. Economic impacts assessment of pleuropneumonia burden and control in Pastoral Cattle Herds of North-Central Nigeria. Bull Anim Health Prod Africa. 2017;65 (2):235-248.

18. Thiaucourt F, Var Der Lugt JJ, Provost A. Contagious bovine pleuropneumonia. In: Coetzer JAW, Tustin RC, editors. Infectious Diseases of Livestock. 2nd ed. Cape Town, Southern Africa: Oxford University Press; 2004:2045-2059.

19. Li Y, Wang Y, Wang R, et al. Changes in pathogenicity and immunogenicity of Mycoplasma mycoides subsp. mycoides strains revealed by comparative genomics analysis. Sci Rep. 2016;6:19081.

20. OIE. Contagious bovine pleuropneumonia (infection with Mycoplasma mycoides subsp mycoides SC). Manual of Diagnostic Tests and Vaccines for Terrestrial Animals. Paris, France: OIE-World Organization for Animal Health; 2018:1097-1112.

21. Done SH, Nicholas RAJ, Palmer N. Contagious bovine pleuropneumonia (CBPP): an emerging disease in Europe. Cattle Pract. 1995;2:1-8.

22. Newton LG, Norris R. Clearing a Continent: The Eradication of Bovine Pleuropneumonia from Australia. Collingwood, Australia: CSIRO Publishing; 2000.

23. Thiaucourt F, Yaya A, Wesonga H, Manso-Silvan L, Blanchard A. Contagious bovine pleuropneumonia vaccines and control strategies: recent data. Dev Biol. 2004;119:99-111.

24. Thomson G Contagious bovine pleuropneumonia possible future strategies for the control of the disease in the PACE region. In: towards sustainable CBPP control programmes for Africa. Proceeding of FAO-OIE-AU/IBAR-IAEA Consultative Group on CBPP. 3rd Meeting, 12-14 November. Food and Agriculture Organization of the United Nations (FAO), Rome; 2003.

25. Masiga WN, Domenech J, Windsor RS. Manifestation and epidemiology of contagious bovine pleuropneumonia in Africa. Rev Sci Tech. 1996;15:1283-1303. doi:10.20506/rst.15.4.980

26. Wesonga HO, Thiaucourt F. Experimental studies on the efficacy of T1SR and T1/44 vaccine of Mycoplasma mycoides subspecies mycoides (small colony) against a field isolate causing contagious bovine pleuropneumonia in Kenya - effect of are vaccination. Rev Elev Med Vet Pays Trop. 2000;3:313-318. doi:10.19182/remvt.9707

27. OIE. Terrestrial Animal Health Code. Paris, France: Office international des epizooties; 2005.

28. AU-IBAR. Pan African Animal Health Yearbook. Nairobi, Kenya: African Union-Interafrican Bureau for Animal Resources;2002. ISSN 1811-007X.

29. Di Teodoro G, Marruchella G, Di Provvido A, et al. Contagious Bovine Pleuropneumonia: a comprehensive overview. Vet Pathol. 2020;1-14.

30. Vilei EM, Abdo E-M, Nicolet J, Botelho A, Gonçalves R, Frey J. Genomic and antigenic differences between the European and African/Australian clusters of Mycoplasma mycoides subsp. mycoides SC. Microbiol. 2000;146:477-486. doi:10.1099/ 00221287-146-2-477

31. Terlaak EA. Contagious bovine pleuropneumonia. A review. Vet Quart. 1992;15:104-110. doi:10.1080/01652176.1992.9694343

32. Alhaji NB Epizootiology of Contagious Bovine Pleuropneumonia in Niger State, Nigeria [Ph.D Thesis]. Department of Veterinary Public Health and Preventive Medicine, Faculty of Veterinary Medicine, University of Ibadan, Ibadan, Nigeria; 2015:Xxiii + 320 . 
33. Muuka G, Otina B, Wesonga H, Bowa B, Gicheru N, Stuke K. Evaluation of new generation macrolides for the treatment and metaphylaxis of contagious bovine pleuropneumonia (CBPP) in cattle experimentally infected with Mycoplasma mycoides subspecies mycoides. BMC Vet Res. 2019;15(1):451-463. doi:10.1186/s12917-019-2197-x

34. Ayling R. Contagious Bovine Pleuropneumonia. IOM Newslett. 2013;37:10-15

35. Masiga WN, Read WCS. Comparative susceptibility of Bos indicus and Bos taurus to contagious bovine pleuropneumonia and the efficacy of the T1 broth culture vaccine. Vet Rec. 1972;90 (18):499-502. doi:10.1136/vr.90.18.499

36. Abdela N, Yune N. Seroprevalence and distribution of Contagious Bovine Pleuropneumonia in Ethiopia: update and critical analysis of 20 years (1996-2016) reports. Front Vet Sci. 2017;4:100. doi:10.3389/fvets.2017.00100

37. Nwanta JN, Umoh JU. The epidemiology of contagious bovine pleuropneumonia (CBPP) in northern states of Nigeria: an update. Rev Elev Med Vet Pays Trop. 1992;45:17-20.

38. Twinamasiko EK Development of an appropriate programme for the control of contagious bovine pleuropneumonia in Uganda $[\mathrm{PhD}$ Thesis]. University of Reading, United Kingdom; 2002:xvii + 191.

39. Chima JC, Mohammed A, Lombin LH, Majiyagbe KA Field validation of a monoclonal antibody-based competitive ELISA for the detection of antibodies to contagious bovine pleuropneumonia. Proceedings of 2nd RCM of IAEA/FAO CRP on Monitoring of CBPP in Africa using ELISA, Lusaka, Zambia, September 27 - October 1; 1999:11-17.

40. Alhaji NB, Babalobi OO. Sero-positivity and associated risk factors of contagious bovine pleuropneumonia under two cattle production systems in North-central Nigeria. Trop Anim Health Prod. 2016;43(2):311-320. doi:10.1007/s11250-015-0952-y

41. Masiga WN, Roberts DH, Kakoma I, Rurangirwa FR. Passive immunity to contagious bovine pleuropneumonia. Res Vet Sci. 1975;19:330-332. doi:10.1016/S0034-5288(18)33511-2

42. Scudamore JM. Observation on the epidemiology of contagious bovine pleuropneumonia: mycoplasma mycoides mycoides small colony in urine. Res Vet Sci. 1076;20:330-333. doi:10.1016/ S0034-5288(18)33432-5

43. Gonçalves R, Regalla J, Nicolet J, et al. Antigen heterogeneity among Mycoplasma mycoides subsp. mycoides SC isolates: discrimination of major surface proteins. Vet Microbiol. 1998;63:13-28. doi:10.1016/S0378-1135(98)00214-4

44. Windsor RS, Masiga WN. Investigations into the epidemiology of CBPP: the persistence of Mycoplasma mycoides subsp. mycoides in placenta, urine and hay. Bull Epiz Dis Africa. 1977;25:357-370.

45. Davies G. Contagious Bovine Pleuropneumonia. What every Veterinarian ought to know. State Vet J. 1994;1:9-11.

46. Goncalves R, Regalla I, Penha-Goncalves A. Immunoblotting and electrophoretic analysis of Mycoplasma mycoides subsp. mycoides SC strains isolated from bovine and small ruminants. Intern Org Mycoplasmol Lett. 1994;3:64-71.

47. Brandao E. Isolation and identification of Mycoplasma mycoides subspecies mycoides SC strains in sheep and goats. Vet Rec. 1995;136(4):98-99. doi:10.1136/vr.136.4.98

48. FAO/EMPRES/TADs. Contagious bovine pleuropneumonia; 2004. Available from: http://www.fao.org/ag/againfo/pro grammes/en/empres/disease_cbpp.asp. Accessed August 10, 2013.

49. Provost A, Perreau P, Beard A, Le Goff C, Martel JL, Cottew GS. Contagious bovine pleuropneumonia. Rev Sci Tech 1987;6:625-679. doi:10.20506/rst.6.3.306

50. Nicholas R, Ayling R, McAuliffe L. Contagious Bovine Pleuropneumonia. Mycoplasma Diseases of Ruminants. UK: CABI, Publishing; 2008:69-97.
51. OIE. Contagious bovine pleuropneumonia. In: Manual of Diagnosis Tests and Vaccines. 5th ed; 2008:712-724

52. Radostits OM, Gay CC, Hinchcliff KW, Constable PD. Veterinary Medicine. A Text Book of Diseases of Cattle, Sheep, Pigs, Goats and Horses. 10th ed. London: W.B. Saunders Elsevier; 2007:1125-1131.

53. Olorunshola ID, Andrew RP, Scacchia M, Nicholas RAJ. Contagious bovine pleuropneumonia - never out of Africa? Rev. 2017;12(019):1-7.

54. FAO. Can contagious bovine pleuropneumonia (CBPP) be eradicated? Food and Agriculture Organization of the United Nations (FAO) Animal Production and Health Proceedings No. 19, Rome, Italy; 2016.

55. AU-IBAR. Contagious Bovine Pleuropneumonia. Animal Health and Production Compendium. African Union-Interafrican Bureau for Animal Resources, Nairobi, Kenya. UK: CAB Publishing; 2019. Available from: https://www.au-ibar.org/contagious-bovine-pleurop neumonia. Accessed July 30, 2012.

56. Alhaji NB, Babalobi OO. The Sero-prevalence and seasonality of contagious bovine pleuropneumonia in nomadic pastoral cattle herds of Niger State, Nigeria. Trop Vet. 2016;34(3\&4):73-81.

57. Rosendal S. Mycoplasma. Pathogenesis of Bacterial Infections in Animals. 2nd ed. Ames, IA: Iowa State University; 1993:297-311

58. Walker LR. Mollicutes. In: Hirsh DC, Zee YC, editors. Veterinary Microbiology. Blackwell Science, Inc.; 1999:165-172.

59. FAO. Recognizing contagious bovine pleuropneumonia. Food and Agriculture Organization of the United Nations (FAO) Animal Health Manual No. 13. Rome, Italy; 2002.

60. Bashiruddin JB, Santini FG, De Santis P, et al. Detection of Mycoplasma mycoides subspecies mycoides in tissues from an outbreak of contagious bovine pleuropneumonia by culture, immunohistochemistry and polymerase chain reaction. Vet Rec. 1999;145:271-274. doi:10.1136/vr.145.10.271

61. Trichard CJV, Basson PA, Vanderlugt JJ, Jacobsz EJ. An outbreak of contagious bovine pleuropneumonia in the Owambo Mangetti area of south west Africa/Namibia: microbiological, immunofluorescent, pathological and serological findings. Onderstepoort $J$ Vet Res. 1981;56:277-284.

62. Amanfu W, Sediadie S, Masupu KV, et al. Comparison between c-ELISA and CFT in detecting antibodies to Mycoplasma mycoides mycoides biotype SC in cattle affected by CBPP in Botswana. Ann NY Acad Sci. 2000;916:364-369. doi:10.1111/ j.1749-6632.2000.tb05314.x

63. Bellin S, Giovannini A, Di Francesco C, Tittarelli M, Caporale V. Sensitivity and specificity of serological and bacteriological tests for contagious bovine pleuropneumonia. Rev Sci Tech. 1998;17:654-659. doi:10.20506/rst.17.3.1124

64. Le Goff C, Thiaucourt F. A competitive ELISA for the specific diagnosis of contagious bovine pleuropneumonia (CBPP). Vet Microbiol. 1998;60:179-191. doi:10.1016/S0378-1135(98)00156-4

65. Thiaucourt F, Yaya A, Wesonga H, Hübschle OJB, Tualasne JJ, Provost A. Contagious bovine pleuropneumonia, a reassessment of the efficacy of vaccines in Africa. Ann NY Acad Sci. 2000;916:71-80. doi:10.1111/j.1749-6632.2000.tb05276.x

66. Marobela-Raborokgwe C, Nicholas R, Ayling R, et al. Comparison of complement fixation test, immunoblotting, indirect ELISA, and competitive ELISA for detecting antibodies to Mycoplasma mycoides subspecies mycoides small colony (SC) in naturally infected cattle from the 1995 outbreak in Botswana. Onderstepoort J Vet Res. 2003;70(1):21-27.

67. Matua-Alumira RW, Ng'ang'a Z, Kiara H, et al. The Prevalence of Contagious Bovine Pleuropneumonia (CBPP) in cattle under different production systems in Kajiado District, Kenya. Proceedings of the 11th International Symposium on Veterinary Epidemiology and Economics; 2006. Available from: www.sci quest.org.nz. Accessed July 23, 2017. 
68. CIRAD/Institut Pourquier. Serological Detection of Specific Antibodies to Mycoplasma Myicoides Mycoides Subsp. Mycoides Small Colony (Mmmsc). The aetiologic agent of Contagious Bovine Pleuropneumonia (CBPP); 2010.

69. Abdo EM, Nicolet J, Frey J. Antigenic and genetic characterization of lipoprotein LppQ from Mycoplasma mycoides subsp. mycoides SC. Clin Diagn Lab Immunol. 2000;7:588-595. doi:10.1128/CDLI.7.4.588-595.2000

70. Rice P, Houshaymi BM, Nicholas RA, Miles RJ. A rapid biochemical test to aid identification of Mycoplasma mycoides subsp. mycoides small colony (SC) strains. Lett Appl Microbiol. 2000;30:70-74. doi:10.1046/j.1472-765x.2000.00674.x

71. Le Grand D, Saras E, Blond D, Solsona M, Poumarat F. Assessment of PCR for routine identification of species of the Mycoplasma mycoides cluster in ruminants. Vet Res. 2004;35:635-649. doi:10.1051/vetres:2004037

72. Bashiruddin JB, Taylor TK, Gould AR. A PCR-based test for the specific identification of Mycoplasma mycoides subsp. mycoides SC. $J$ Vet Diagn Invest. 1994;6:428-434. doi:10.1177/ 104063879400600405

73. Dedieu L, Mady V, Lefevre PC. Development of a selective polymerase chain-reaction Assay for the detection of Mycoplasma mycoides subsp. mycoides SC. Vet Microbiol. 1994;42:327-339. doi:10.1016/0378-1135(94)90064-7

74. Miserez R, Pilloud T, Cheng X, Nicolet J, Griot C, Frey J. Development of a sensitive nested PCR method for the specific detection of Mycoplasma mycoides subsp. mycoides SC. Mol Cell Probes. 1997;11:103-111. doi:10.1006/mcpr.1996.0088

75. Alhaji NB, Babalobi OO. Molecular epidemiology of contagious bovine pleuropneumonia by detection, identification and differentiation of Mycoplasma mycoides subsp. mycoides in Niger State, Nigeria. Sokoto J Vet Sci. 2015;13(3):1-8.

76. Ankeli PI, Raji MA, Kazeem HM, et al. Isolation and identification of Mycoplasma mycoides subspecies mycoides from the ear canal of cattle in Plateaus State, North-central Nigeria. Vet Sci Res Rev. 2016;2(2):52-59.

77. Rawadi G, Lemercier B, Roulland-Dussoix D. Application of an arbitrarily-primed polymerase chain reaction to mycoplasma identification and typing within the Mycoplasma mycoides cluster. J Appl Bacteriol. 1995;78(6):586-592. doi:10.1111/ j.1365-2672.1995.tb03103.x

78. Persson A, Petterson B, Bolske G, Johansson KE. Diagnosis of contagious bovine pleuropneumonia by PCR-lazer induced fluorescence and PCR-Restriction endonuclease analysis based on 16SrRNA genes of Mycoplasma mycoides subspecies mycoides Small Colony. J Clin Microbiol. 1999;37:3815-3821. doi:10.1128/JCM.37.12.3815-3821.1999

79. Vilei EM, Frey J. Genetic and biochemical characterization of glycerol uptake in Mycoplasma mycoides subsp. mycoides SC: its impact on $\mathrm{H}_{2} \mathrm{O}_{2}$ production and virulence. Clin Diagnost Lab Immunol. 2001;8:85-92. doi:10.1128/CDLI.8.1.85-92.2001

80. Hotzel H, Sachse K, Pfützner H. A PCR scheme for differentiation of organisms belonging to the Mycoplasma mycoides cluster. Vet Microbiol. 1996;49(1/2):31-43. doi:10.1016/0378-1135(95) 00176-X

81. Lorenzon S, Arzul I, Peyraud A, Hendrikx P, Thiacourt F. Molecular epidemiology of contagious bovine pleuropneumonia by multilocus sequence analysis of Mycoplasma mycoides subspecies mycoides biotype SC strains. Vet Microbiol. 2003;93 (4):319-333. doi:10.1016/S0378-1135(03)00043-9

82. Cheng X, Nicolet J, Poumarat F, Regalla J, Thiaucourt F, Frey J. Insertion element IS1296 in Mycoplasma mycoides subsp. mycoides small colony identifies a European clonal line distinct from African and Australian strains. Microbiol. 1995;141:3221-3228. doi:10.1099/13500872-141-12-3221
83. Miles K, Churchward CP, McAuliffe L, Ayling RD, Nicholas RAJ. Identification and differentiation of European and African/Australian strains of Mycoplasma mycoides subspecies mycoides small-colony type using polymerase chain reaction analysis. J Vet Diagn Invest. 2006;18(2):168-171. doi:10.1177/ 104063870601800205

84. Mahillon J, Chandler M. Insertion sequences. Microbiol Mol Biol Revis. 1998;62:725-774.

85. March JB, Clark J, Brodlie M. Characterization of strains of Mycoplasma mycoides subsp. mycoides small colony type isolated from recent outbreaks of contagious bovine pleuropneumonia in Botswana and Tanzania: evidence for a new biotype. J Clin Microbiol. 2000;38:1419-1425. doi:10.1128/JCM.38.4.14191425.2000

86. Frey J, Cheng X, Kuhnert P, Nicolet J. Identification and characterization of IS1296 in Mycoplasma mycoides subsp. mycoides $\mathrm{SC}$ and presence in related mycoplasmas. Gene. 1995;160:95-100. doi:10.1016/0378-1119(95)00195-C

87. Vilei EM, Nicolet J, Frey J. IS1634, a novel insertion element creating long, variable-length direct repeats which is species for Mycoplasma mycoides subsp. mycoides small-colony type. J Bacteriol. 1999;181:1319-1323. doi:10.1128/JB.181.4.13191323.1999

88. de Leeuw PN, McDermott JJ, Lebbie SHB. Monitoring of livestock health and production in sub-Saharan Africa. Prev Vet Med. 1995;25:195-212. doi:10.1016/0167-5877(95)00547-1

89. Catley A. The use of participatory epidemiology to compare the clinical and veterinary knowledge of pastoralist and veterinarians in East Africa. Trop Anim Health Prod. 2006;38:171-184. doi:10.1007/s11250-006-4365-9

90. Catley A Participatory Epidemiology: A Guide for Trainers. African Union/Inter-African Bureau for Animal Resources, Nairobi; 2005. Available from: http://www.participatoryepidemiol ogy.info/copy/pdf. Accessed November 23, 2013.

91. Thrusfield M. Veterinary Epidemiology. 3rd ed. 9600 Garsington Road, Oxford OX4 2DQ, UK: Blackwell Science Ltd, a Blackwell Publishing company; 2009.

92. Jost CC, Mariner JC, Roeder PL, Sawitri E, Macgregor-Skinner GJ. Participatory epidemiology in disease surveillance and research. Rev Sci Tech. 2007;26(3):537-547. doi:10.20506/ rst.26.3.1765

93. Alhaji NB, Babalobi OO. Participatory epidemiology of ethnoveterinary practices fulani pastoralists used to manage contagious bovine pleuropneumonia and other cattle ailments in Niger State, Nigeria. J Vet Med. 2015;Article ID 460408:10.

94. Mariner JC, Paskin R Manual on participatory epidemiology. Methods for the collection of action-oriented epidemiological intelligence. Food and Agriculture Organization of the United Nations (FAO) Animal Health Manual No. 10. Rome, Italy: FAO; 2000.

95. Catley A, Osman J, Mawein C, Jones BA, Leyland TY. Participatory analysis of seasonal incidences of diseases of cattle, disease vectors and rainfall in Southern Sudan. Prev Vet Med. 2002;53:275-284. doi:10.1016/S0167-5877(01)00289-6

96. Muuka GM, Chikampa W, Mundia C, et al. Recent observations on site reactions in cattle to vaccination against contagious bovine pleuropneumonia (CBPP) using T1/44 vaccine in Zambia. Trop Anim Health Prod. 2014;46(2):481-483. doi:10.1007/s11250013-0429-9

97. Amanfu W. Contagious bovine pleuropneumonia (lung sickness) in Africa. Onderstepoort $J$ Vet Res. 2009;76(1):13-17. doi:10.4102/ojvr.v76i1.55

98. OIE. Manual of Diagnostic Tests and Vaccines for Terrestrial Animals (Mammals, Birds and Bees). 6th ed. Paris: Office the International Des Epizooties; 2008:712-724. 
99. Rweyemamu M, Paskin R, Benkirane A, Martin V, Roeder P, Wojciechowski K Emerging diseases of Africa and the Middle East. Annals of the New York Academy of Sciences [Tropical veterinary diseases: control and prevention in the context of the New World Order]. Proceedings of the Fifth Biennial Conference of the Society for Tropical Veterinary Medicine, held on June 12-16, 1999, in Key West, Florida, USA; Vol. 916; 2000:61-70

100. Mariner JC, McDermott J, Heesterbeek JAP, Thomson G, Martin SW. A model of Contagious Bovine Pleuropneumonia transmission dynamics in East Africa. Prev Vet Med. 2006;73 (1):55-74. doi:10.1016/j.prevetmed.2005.09.001

101. Msami HM, Ponela-Mlewa T, Mutei BJ, Kapaga AM. Contagious bovine pleuropneumonia in Tanzania: current status. Trop Anim Health Prod. 2001;33(1):21-28. doi:10.1023/A:1010377325566

102. Yaya A, Wesonga $H$, Thiaucourt $F$ Use of long-acting tetracycline for CBPP: preliminary results. Proceedings-Towards sustainable CBPP control programmes for Africa. FAO-OIE-AU/IBAR Consultative Group on Contagious Bovine Pleuropneumonia. 3rd Meeting, 12-14 November, 2003; Rome; 2004.

103. Hübschle OJ, Ayling RD, Godinho K, et al. Danofloxacin (Advocin) reduces the spread of contagious bovine pleuropneumonia to healthy in-contact cattle. Res Vet Sci. 2006;81:304-309. doi:10.1016/j.rvsc.2006.02.005

104. Niang M, Sery A, Doucouré M, et al. Experimental studies on the effect of long-acting oxytetracycline treatment in the development of sequestra in contagious bovine pleuropneumonia-infected cattle. J Vet Med Anim Health. 2010;2:35-45.

105. Hubschle O, Godinho K, Nicholas RAJ. Danofloxacin treatment of cattle affected by CBPP. Vet Rec. 2004;155:404.

106. Abd-Elrahman AH, Khafaga AF, Abas OM. The first identification of contagious caprine pleuropneumonia (CCPP) in sheep and goats in Egypt: molecular and pathological characterization. Trop Anim Health Prod. 2019;1-8.

107. Morobela RC. Contagious bovine pleuropneumonia in Botswana: experience with control, eradication, prevention and surveillance. Vet Ital. 2011;47(4):397-405.

108. Amanfu W, Masupu KV, Adom EK, Raborokgwe MV, Bashiruddin JB. An outbreak of contagious bovine pleuropneumonia in Ngamiland district of north-western Botswana. Vet Rec. 1998;143(2):46-48. doi:10.1136/vr.143.2.46

109. Jores J, Mariner JC, Naessens J. Development of an improved vaccine for contagious bovine pleuropneumonia: an African perspective on challenges and proposed actions. Vet Res. 2013;44:122. doi:10.1186/1297-9716-44-122

110. Scacchia M, Sacchini F, Filipponi G, et al. Clinical, humoral and IFNgamma responses of cattle to infection with Mycoplasma mycoides var. mycoides small colony and attempts to condition the pathogenesis of the infection. Onderstepoort $J$ Vet Res. 2007;74(3):251-263. doi:10.4102/ojvr.v74i3.128
111. Mulongo MM, Frey J, Smith K, et al. Cattle immunized against the pathogenic 1-alpha-glycerol-3-phosphate oxidase of Mycoplasma mycoides subsp. mycoides fail to generate neutralizing antibodies and succumb to disease on challenge. Vaccine. 2013;31:5020-5025. doi:10.1016/j.vaccine.2013.08.100

112. Dedieu L, Balcer-Rodrigues V, Yaya A, et al. Gamma interferon producing CD4 T-cells correlate with resistance to Mycoplasma mycoides subsp. mycoides SC infection of cattle. Vet Immunol Immunopathol. 2005;107(3-4):217-233. doi:10.1016/j. vetimm.2005.04.011

113. Sacchini F, Naessens J, Awino E, et al. A minor role of CD4+ $\mathrm{T}$ lymphocytes in the control of a primary infection of cattle with Mycoplasma mycoides subsp. mycoides. Vet Res. 2011;42:77-85. doi:10.1186/1297-9716-42-77

114. Dedieu L, Balcer-Rodrigues V, Cisse O, Diallo M, Niang M. Characterisation of the lymph node immune response following Mycoplasma mycoides subsp. mycoides SC infection in cattle. Vet Res. 2006;374:579-591. doi:10.1051/vetres:2006020

115. Totte P, Rodrigues V, Yaya A, et al. Analysis of cellular responses to Mycoplasma mycoides subsp. mycoides small colony biotype associated with control of contagious bovine pleuropneumonia. Vet Res. 2008;39(1):8-15. doi:10.1051/vetres:2007046

116. Totte P, Duperray C, Dedieu L. CD62L defines a subset of pathogen specific bovine CD4 with central memory cell characteristics. Dev Comp Immunol. 2010;34(2):177-182. doi:10.1016/j.dci.2009.09.005

117. Jores J, Nkando I, Sterner-Kock A, et al. Assessment of in vitro interferon-gamma responses from peripheral blood mononuclear cells of cattle infected with Mycoplasma mycoides subsp. mycoides small colony type. Vet Immunol Immunopathol. 2008;124(1-2):192-197. doi:10.1016/j.vetimm.2008.02.019

118. Schoenborn JR, Wilson CB. Regulation of interferon-gamma during innate and adaptive immune responses. Adv Immunol. 2007;96:41-101.

119. Balcer V, Dedieu L. Cell mediated immunity induced in cattle by Mycoplasma mycoides subsp. mycoides: comparison between infected and vaccinated animals. In: Bergonnier D, Berthelot X, Frey J, editors. Mycoplasma of Ruminants: Pathogenicity, Diagnostics, Epidemiology and Molecular Genetics (Cost 826). Luxembourg: European Union, Agriculture and Biotechnology. EUR 19245; 2000:97-100.

120. Abusugra I, Wolf G, Bolske G, Thiaucourt F, Morein B. ISCOM vaccine against contagious bovine pleuropneumonia (CBPP). Biochemical and immunological characterization. Vet Immunol Immunopathol. 1997;59:31-48. doi:10.1016/S0165-2427(97) 00067-6

\section{Publish your work in this journal}

Veterinary Medicine: Research and Reports is an international, peerreviewed, open access journal publishing original research, case reports, editorials, reviews and commentaries on all areas of veterinary medicine. The manuscript management system is completely online and includes a very quick and fair peer-review system. Visit http://www.dovepress.com/testimonials.php to read real quotes from published authors. 